ISSN: 2224-0616

Int. J . Agril. Res. Innov. \& Tech. 8 (1): 18-25, J une, 2018

Available online at http:// www.ijarit.webs.com

\title{
EVALUATION OF POSTHARVEST QUALITY OF EDIBLE COATED MANDARIN AT AMBIENT STORAGE
}

\author{
T.A.A. Nasrin*1, M.N. Islam ${ }^{2}$, M.A. Rahman', M.S. Arfin ${ }^{3}$ and M.A. Ullah ${ }^{4}$ \\ Received 20 December 2017, Revised 8 June 2018, Accepted 26 June 2018, Published online 30 June 2018
}

\begin{abstract}
An experiment was conducted to assess the influence of edible coatings on postharvest quality of mandarin during 20 days of ambient storage. Sorted fruits were washed; fruit surface water was removed and then coated with $100 \%$ liquid paraffin wax, $0.5 \%$ chitosan, $1.0 \%$ chitosan, $1.5 \%$ chitosan, and $100 \%$ coconut oil. After coating, fruit surface was air dried and kept at ambient condition $\left(25 \pm 3{ }^{\circ} \mathrm{C}, 60-70 \% \mathrm{RH}\right)$ and analyzed periodically for weight loss, respiration rate, firmness, decay incidence, TSS, $\mathrm{pH}$, ascorbic acid content, and sensory properties. The results revealed that coconut oil had immense effect on the reduction of the weight loss and respiration rate and preserved firmness, total soluble solids, ascorbic acid, total sugar and reducing sugar and no incidence of moulds \& their growth was found up to 16 days of storage.
\end{abstract}

Keywords: Coconut Oil, Sensory Quality, Respiration Rate, Firmness, Ascorbic Acid

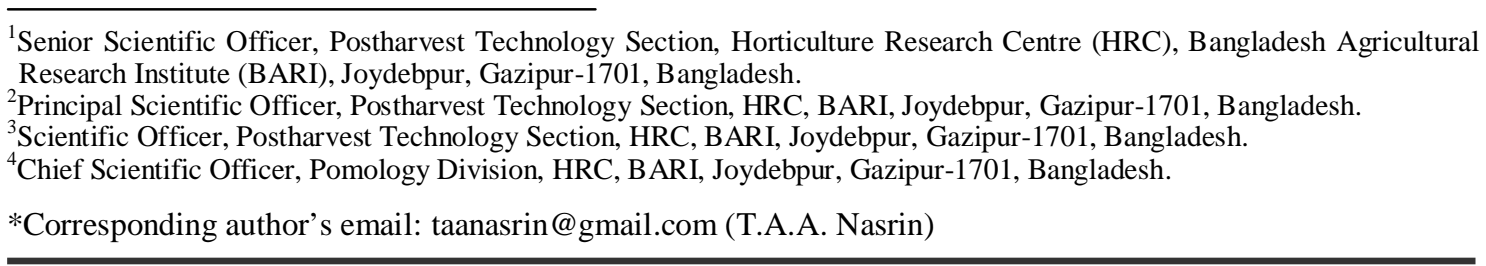

\section{Introduction}

Mandarin, Citrus reticulata is a member of citrus family along with orange, lemons, limes and grapefruit. Citrus fruits are said to be the first crops in the international trade in terms of values (CIAC, 2002). Mandarin is made up of soft texture, and the edible materials are very important in human diet since they contain essential vitamins and minerals. Mandarin being a non climacteric fruits harvested at matured stage and after harvest the important post harvest requirement is the extension of shelf life by maintaining its quality. Postharvest quality can be retained or losses can be reduced through controlling the rate of transpiration, respiration, microbial infection and protecting membranes from carelessness (Bisen and Pandey, 2008).

These objectives can be reached to some extent by the use of growth regulators, edible coating, waxing, storage at low temperature, use of fungicide, chemical application, oil coating, irradiation and different types of packing material as post harvest treatments (Bisen et al., 2008; Chahal and Bal, 2003). Though these modern technologies exist the post harvest losses of fruit is still high. The majority of the farmers in Bangladesh are small and marginal; they do not have modern facilities and are not able to effort the costly post harvest treatments as well as lack of knowledge about these techniques among growers. Therefore, alternative low cost technologies that should be easily available, economically viable and feasible considering health and environmental issues need to be standardized. Among the different low cost technologies, the application of edible coating to fruit has gained interest globally as these coating protect perishables from deterioration by reducing respiration, improving textural quality, helping retain volatile flavour compounds and reducing microbial growth (Mahfoudhi et al., 2014).

Pure coconut oil as edible coating of fruits has gaining interest for its anti-senescence property by controlling respiration rate, transpiration rate and binding of the ethylene biosynthesis process. Coconut oil and liquid paraffin coating closed the opening of stomata and lenticels thereby, reducing the transpiration and respiration rate and also reduce microbial activity (Bisen et al., 2012). On the other hand, chitosan a modified natural biopolymer obtained from shell fish waste possesses excellent film forming capacity, barrier property and some level of anti-microbial property as well (Aday and Caner, 2010). Chitosan coatings have been reported to limit fungal decay and delay the ripening of several commodities, including strawberry (Han et al., 2004; Ribeiro et al., 2007).

Keeping these in mind, the present investigation was conducted to find out suitable edible coating for preserving postharvest quality of mandarin. Assessment of the treatments was based on their 
effects on physical, chemical, microbiological, and sensory quality attributes of mandarin stored for 20 days at ambient condition $\left(25 \pm 3{ }^{\circ} \mathrm{C}, 60\right.$ $70 \% \mathrm{RH})$.

\section{Materials and Methods}

Mandarin (var. BARI Kamola-1) was collected from Fruit Research Farm of Agriculture Research Station (ARS), Raikhali, Bangladesh. They were placed in carton boxes and immediately transported to the research laboratory in Postharvest Technology Section, Bangladesh Agriculture Research Institute (BARI), Gazipur for this study. Fruits were selected for uniformity in maturity, shape and size and free of physical damage and infection. Chitosan-652 (high molecular weight) was purchased from Mahtani Chitosan Pvt. Ltd, India. Other chemicals used in this study were chemical grade.

\section{Preparation of chitosan solution}

To prepare $100 \mathrm{~mL}$ of $0.5 \%, 1.0 \%$, or $1.5 \%$ chitosan solution, $0.5,1.0$ or $1.5 \mathrm{~g}$ of chitosan, respectively was dissolved in $75 \mathrm{~mL}$ of distilled water added with $2 \mathrm{~mL}$ of glacial acetic acid. The mixture was heated with continuous stirring $\left(55^{\circ} \mathrm{C}\right.$ and $\left.500 \mathrm{rpm}\right)$ for proper dissolution of chitosan. The final $\mathrm{pH}$ of the solution was adjusted to 5.6 with $2 \mathrm{~N} \mathrm{NaOH}$ and volume was made up to $100 \mathrm{~mL}$ with sterilized distilled water (Jiang and Li, 2001).

\section{Application of coating}

Fruits were washed by normal tap water. Water from fruit surface were removed with tissue paper and then kept in air, thus ready to be used for coating application. Washed fruits were divided into 6 groups (150 fruits/ group or treatment and 3 replications/ treatment). Each group was treated by different treatments including: 1) Control or uncoated fruits, 2) fruits were coated with $100 \%$ liquid paraffin wax, 3) fruits were coated with $0.5 \%$ chitosan solution, 4 ) fruits were coated with $1.0 \%$ chitosan solution, 5) fruits were coated with $1.5 \%$ chitosan solution and 6) fruits were coated with $100 \%$ coconut oil. For chitosan coating, fruits were dipped in different concentration of chitosan solution for $1 \mathrm{~min}$ and then air dried. For liquid paraffin or coconut oil coating, it was applied directly to fruit skin. All treatments were stored at ambient condition $\left(25 \pm 3^{\circ} \mathrm{C}\right.$ and $\left.60-70 \% \mathrm{RH}\right)$. The observations on various physico-chemical attributes were taken on same day of harvest and after 4, 8, 12, 16 and 20 days of storage. From each replication, 10 fruits were kept separately for weight loss and colour change measurement throughout the storage period.

\section{Respiration rate analysis}

Respiration rate of mandarin was assayed on each measurement interval during storage. Five fruits from each replication of different treatments were placed in $4000 \mathrm{~mL}$ airtight plastic containers equipped with septa and sealed for $2 \mathrm{~h}$ (incubation time) at ambient condition. Then one $\mathrm{mL}$ of gas was withdrawn from the headspace of container by a gas-light hypodermic syringe and analyzed using a gas analyzer $\left(\mathrm{CO}_{2} / \mathrm{O}_{2}\right.$ gas analyzer, Quantek Instrument, Model No. 902D, USA). The percentage of $\mathrm{CO}_{2}$ gas in the container was recorded. Thereafter, the respiration rate was calculated using total gas volume, mandarin volume and weight in the container and incubation time.

\section{Firmness/ texture analysis}

Firmness of mandarin was analyzed using Fruit Texture Analyzer (GUSS, Model No. GS25, SA). An $8 \mathrm{~mm}$ diameter stainless steel cylindrical probe with a flat end was used for this measurement. The probe was pushed to a depth of $3 \mathrm{~mm}$ into mandarin (same position of each sample) at a speed of $5 \mathrm{~mm} \mathrm{~s}^{-1}$. The maximum penetration force $(\mathrm{kg})$ was used as firmness value of mandarin. Five whole mandarins (2 opposite location) from each replication of different treatments were analyzed; the mean value of each replication was used.

\section{Measurements of surface colour}

External colour of mandarin was evaluated with a Chroma Meter (Model CR-400, Minolta Corp., Japan). CIE L*a*b* coordinates were recorded using D65 illuminants and a $10^{\circ}$ standard observer as a reference system. $L^{*}$ is lightness, $a^{*}$ (-greenness to + redness) and b* (-blueness to +yellowness) are the chromaticity coordinates. The $\mathrm{a}^{*}$ and $\mathrm{b}^{*}$ values were converted to chroma $\left[\mathrm{C}=\left(\mathrm{a}^{* 2}+\mathrm{b}^{* 2}\right)^{1 / 2}\right]$ and hue angle $\left[\mathrm{h}^{\circ}=\tan ^{-}\right.$ $\left.{ }^{1}\left(\mathrm{~b}^{*} / \mathrm{a} *\right)\right]$ automatically in this Chroma meter. Before measurement, calibration against a standard white tile was done. Ten mandarins from each replication of different treatments were analyzed; the mean value of each treatment was used.

\section{Weight loss determination}

Mandarins (ten) from each replication of different treatments were weighed at the beginning of the experiment just after coating and air-drying of fruit surface and thereafter 4 day's interval (same fruits) during the storage period. Weight loss was expressed as the percentage of the initial total weight.

\section{Ascorbic acid, sugar (total, reducing), pH and total soluble solids (TSS) content measurement}

After firmness analysis, mandarin peel was removed and juice was used to assess the chemical parameters. The ascorbic acid content was determined by using 2, 6-dichlorophenol indophenol titration method as described in AOAC (1994). The $\mathrm{pH}$ of the sample (mandarin juice) was assessed using a $\mathrm{pH}$ meter (HANNA Instrument Inc, pH-211; Microprocessor, pH Meter, Italy). The TSS of the fruit juice was determined by using a refractometer. Few drops 
were taken on prism of refractometer and direct reading was taken from the scale in meter according to AOAC (1994) to measure TSS. Total sugar and reducing sugar were also determined according to AOAC (1994).

\section{Decay incidence}

All fruits from each replication were visually monitored for microbial decay by 5 panellists with one pathologist during the storage. Mandarins showing any symptoms of microbial incidence were considered decayed. Results were expressed as the percentage of decayed fruits. Infected samples were also analyzed to determine the causal pathogen.

\section{Sensory property}

The sensorial attributes of mandarin (appearance, flavour, texture and overall acceptability) were evaluated at 16 day of storage by a panel of judges consisting of 20 scientific personnel and consumers including both male and female members. Samples were presented for each panelist in a completely randomized order. A 9-point unstructured hedonic scale ranged from like extremely (score 9) to dislike extremely (score 0) was used (Nasrin and Anal, 2015). An average score of 4.5 was considered the limit for acceptability.

\section{Statistical analysis}

A completely randomised design (CRD) was done with three replication for each experiment and mean \pm standard deviation was shown. Analysis of variance (ANOVA) was done according to the procedures of MSTAT-C software. Comparison among data was performed using Duncan's Multiple Range Test (DMRT) $(\mathrm{p}<0.05)$.

\section{Results and Discussion}

\section{Respiration}

Fig. 1 illustrates the effect of different coatings on $\mathrm{CO}_{2}$ production of mandarins stored at ambient condition $\left(25 \pm 3^{\circ} \mathrm{C}\right.$ and $\left.60-70 \% \mathrm{RH}\right)$. Initial respiration rate of mandarin was $34.56 \mathrm{mg} \mathrm{kg}^{-1} \mathrm{~h}^{-1}$ and it was reduced to even less than half when mandarin was coated with different edible coating. Arpaia and Kader (1999) reported that the respiration rate of fresh mandarin was 20-30 $m g ~ \mathrm{~kg}^{-1} \mathrm{~h}^{-1}$ at $20^{\circ} \mathrm{C}$ in their recommendations for maintaining postharvest quality of mandarin in UC Davis. The control samples presented higher respiration rate throughout the storage time compared with coated ones. It was also observed that the respiration rate of mandarins decreased as the concentration of chitosan increased. The elucidation of this observation is that coating produces very thin and fine layer on fruit skin that block the openings of stomata and lenticels reducing transpiration rate, respiration rate and microbial activity as well (Das and Medhi, 1996). Besides, coating makes gas barrier between the fruit tissue and the surrounding environment that modifies internal atmosphere of fruits by depletion of endogenous $\mathrm{O}_{2}$ and a rise in $\mathrm{CO}_{2}$. The intensity of gas $\left(\mathrm{CO}_{2}\right.$ and $\left.\mathrm{O}_{2}\right)$ change of fruits depends on the coating formulation and on the storage conditions of the products. Seehanam and Boonyakiat (2010) observed that the respiration rate of mandarin coated with some commercial coatings stored at room temperature was decreased over uncoated or control fruits. Das and Medhi (1996) reported that coconut oil and castor oil coating on pineapple closed the opening of stomata and lenticels results the reduction of transpiration rate, respiration rate and microbial activity.

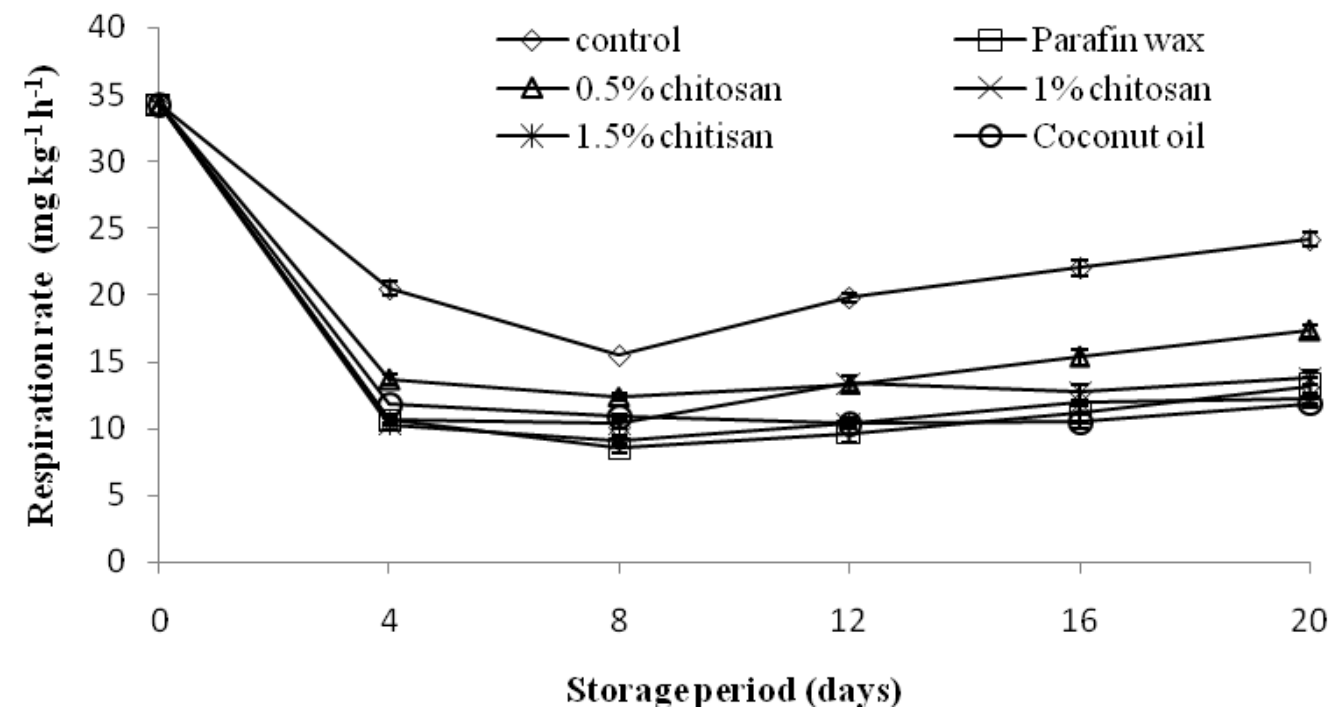

Fig. 1. Effects of edible coatings on the respiration rate of mandarin stored at ambient condition $\left(25 \pm 3^{\circ} \mathrm{C}\right.$ and $\left.60-70 \% \mathrm{RH}\right)$. Vertical bars indicate standard deviation. 


\section{Firmness}

Firmness or texture is a critical quality attribute in the consumer acceptability of fresh fruit and vegetables. Fresh produce suffers a rapid loss of firmness during storage, which enhance greatly to its short postharvest life and susceptibility to fungal contamination. Fruit textural properties are affected by cell turgidity and the structure and composition of the cell wall polysaccharides. Main textural changes resulting in fruit softening are due to enzyme-mediated alterations in the structure and composition of cell walls that lead to partial or complete solubilization, deesterification, and depolymerization of cell-wall polysaccharides, accompanied by a loss of neutral sugars and galacturonic acid (Rosli et al., 2004).

Fig. 2 represents the changes in firmness of control and coated fruits during the storage period of 20 days at ambient condition. Initially the firmness value of mandarin was $0.79 \mathrm{~kg}$ and it was decreased gradually with time but the rate was different for different coating materials. Among the treatment, coconut oil coated mandarin was most firm during the storage period and it lost about 38\% firmness whereas uncoated or control fruits had lost 68\% firmness at 16 days of storage period. Bisen et al. (2012) found that coconut oil coated kagzi lime had the lowest physiological loss in weight (9.67\%) that means maximum firmness and highest amount of marketable fruits $(70 \%)$ retained at 18 days when stored at $\left(25-30{ }^{\circ} \mathrm{C}\right.$ and $\left.60-70 \% \mathrm{RH}\right)$. Chitosan coatings also exerted a beneficial effect on fruit firmness throughout the storage period specially $1.0 \%$ and $1.5 \%$ chitosan coated mandarin preserved their firmness more efficiently than the $0.5 \%$ chitosan coated fruits. The beneficial effect of the elevated chitosan concentration on firmness has also been reported for 'Murcott' tangor (Chien et al., 2007) and peach, Japanese pear and kiwifruit (Du et al., 1997).

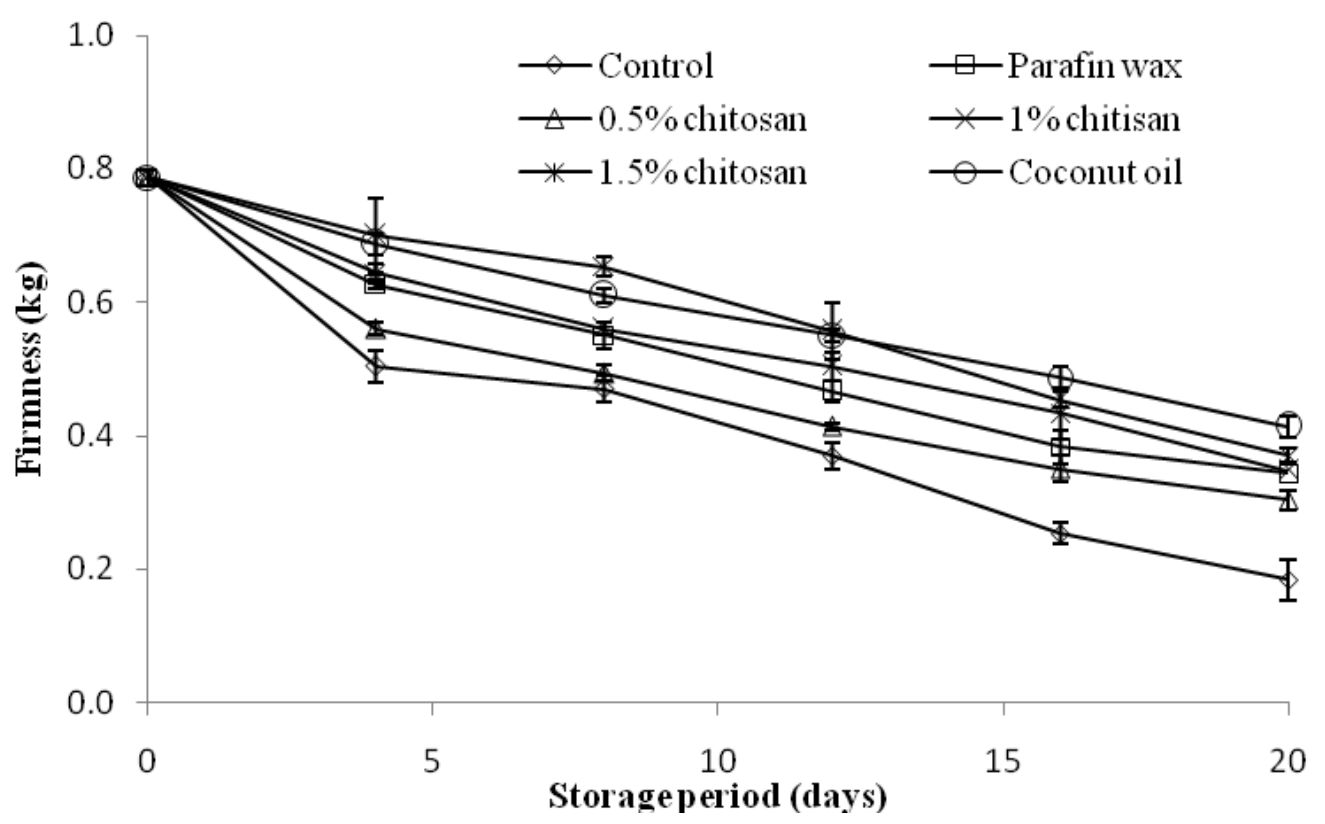

Fig. 2. Effects of edible coatings on firmness of mandarin stored at ambient condition (25 $\pm 3^{\circ} \mathrm{C}$ and $60-70 \% \mathrm{RH}$ ). Vertical bars indicate standard deviation.

\section{Weight loss}

Fruit weight loss is connected with respiration and transpiration through the skin. The rate at which water is lost depends on the water pressure gradient between the fruit tissue and the surrounding atmosphere and storage temperature. Dehydration also cause increase in surface wounding of fruits. Edible coatings act as barriers, thereby restricting water transfer and protecting fruit skin from mechanical injuries, as well as sealing small wounds and thus delaying dehydration. Fig. 3 shows weight loss of uncoated mandarin compared to coated ones during storage at $25 \pm 3^{\circ} \mathrm{C}$ and $60 \%-70 \% \mathrm{RH}$. Weight loss of mandarin, in general, increased with the advancement in storage period. The coating treatments had strong influence on the reduction of the weight loss of mandarin. Fruits coated with pure coconut oil recorded the minimum (about $6 \%$ ) weight loss whereas that was $12 \%$ in control/ uncoated fruits at 16 days of storage (Fig. 3). This may be due to anti senescence property present in pure coconut oil help to slow storage break down associated with slow respiration rate, transpiration rate and binding of the ethylene biosynthesis process (Bisen et al., 2012). 


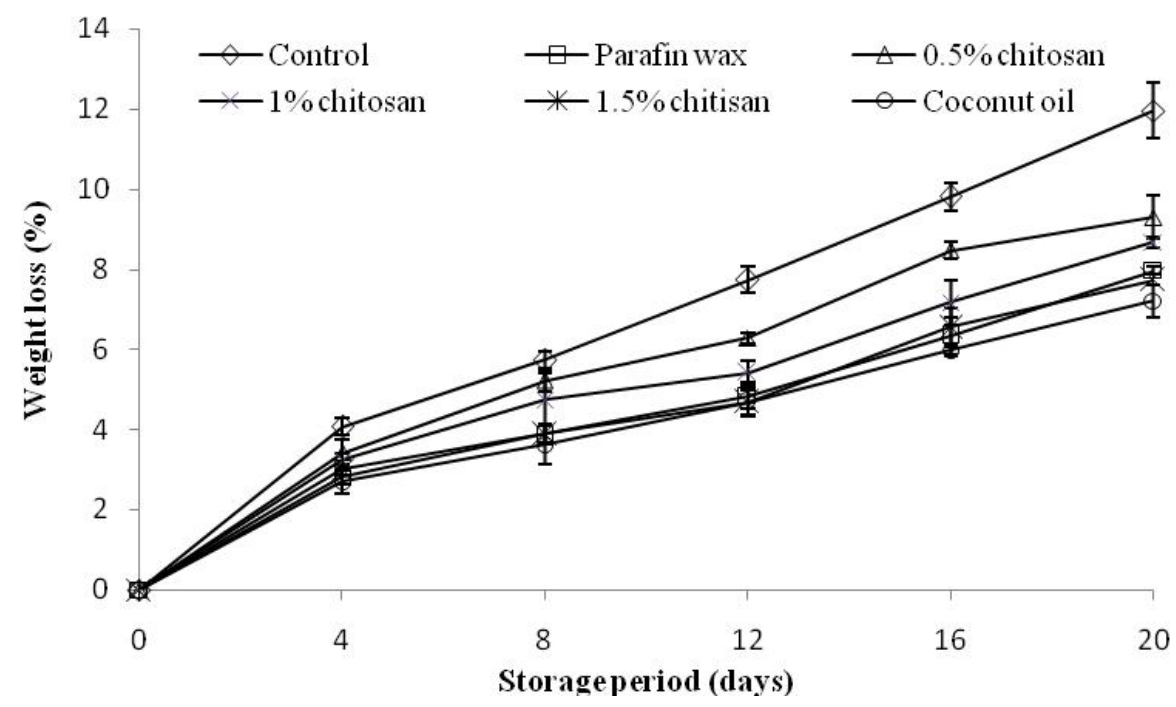

Fig. 3. Effects of edible coatings on the weight loss of mandarin stored at ambient condition $\left(25 \pm 3^{\circ} \mathrm{C}\right.$ and $\left.60-70 \% \mathrm{RH}\right)$. Vertical bars indicate standard deviation.

Coconut oil coating in kagzi lime proved to be significantly superior over control and all other treatment followed by castor oil coating and liquid paraffin wax reported by Bisen et al. (2012). Coconut oil coating and castor oil coating closed the opening of stomata and lenticels results the reduction of transpiration rate, respiration rate and microbial activity (Das and Medhi, 1996). Similar findings were noted by Pandey et al. (2010) in guava fruits.

\section{External fruit colour}

Colour is an important factor in the perception of fruit quality. Fig. 4 illustrates the changes in surface colour of mandarin stored at ambient condition $\left(25 \pm 3^{\circ} \mathrm{C}\right.$ and $\left.60-70 \% \mathrm{RH}\right)$ for 20 days, as given by hue angle. Hue is the term used in the world of colour for the classification of red, yellow, blue, etc. Values of hue angle near $90^{\circ}$ represent yellow colour, while values near $120^{\circ}$ represent green colour. It is well established that the yellowing on citrus fruits might be accessed by changes in hue angle levels. Initial value of hue angle was around $114^{\circ}$ that means greenish colour of mandarins. With storage period the value was decreased and colour of mandarins turn into yellow.

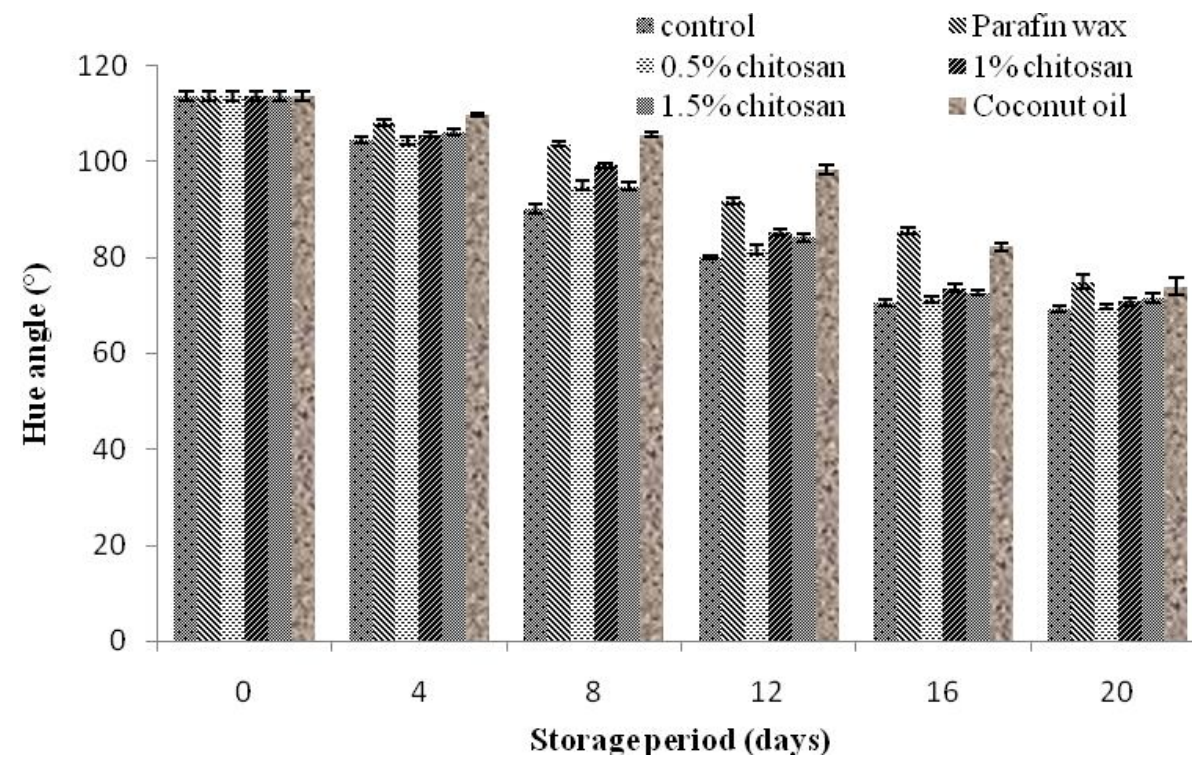

Fig. 4. Effects of edible coatings on the external colour (hue angle) of mandarin stored at ambient condition $\left(25 \pm 3^{\circ} \mathrm{C}\right.$ and $\left.60-70 \% \mathrm{RH}\right)$. Vertical bars indicate standard deviation. 
At 16 days of storage, hue angle value decreased and reached to about $72^{\circ}$ in control and chitosan coated fruits. Whereas mandarin coated with coconut oil and liquid paraffin wax preserves their greenish yellow colour even at 16 days of storage as their hue angle value was around $85^{\circ}$. At 20 days of storage, hue angle of coconut oil coated mandarins were decreased to $74^{\circ}$. Pure coconut oil coating helps to delay in ripening of fruits and uniform colour development of Kagzi lime in later period of storage (Bisen et al., 2012).
Ascorbic acid, sugar (total, reducing), pH and TSS content

Initial ascorbic acid in mandarin was $31.39 \mathrm{mg}$ $100 \mathrm{~g}^{-1}$. The coated fruits preserved more ascorbic acid than control or uncoated one. At 16 days of storage, ascorbic acid content reduced severely to $14.3 \mathrm{mg} 100 \mathrm{~g}^{-1}$ in control or uncoated fruits, while

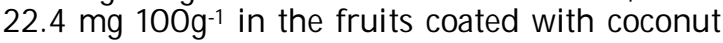
oil.

Table 1. Effect of edible coatings on ascorbic acid, total sugar, reducing sugar, $\mathrm{PH}$ and TSS content of mandarin stored at ambient condition $\left(25 \pm 3^{\circ} \mathrm{C}\right.$ and $\left.60-70 \% \mathrm{RH}\right)$.

\begin{tabular}{|c|c|c|c|c|c|c|c|c|c|c|}
\hline \multirow[t]{2}{*}{ Treatment } & \multicolumn{2}{|c|}{$\begin{array}{c}\text { Ascorbic acid } \\
\left({\left.\mathrm{mg} 100 \mathrm{~g}^{-1}\right)}\right.\end{array}$} & \multicolumn{2}{|c|}{$\mathrm{PH}$} & \multicolumn{2}{|c|}{ TSS (\%) } & \multicolumn{2}{|c|}{ Total sugar (\%) } & \multicolumn{2}{|c|}{$\begin{array}{l}\text { Reducing } \\
\text { sugar (\%) }\end{array}$} \\
\hline & 0 day & 16 day & 0 day & 16 day & 0 day & 16 day & 0 day & 16 day & 0 day & 16 day \\
\hline Control & 31.39 & $14.3 \mathrm{~d}$ & 4.1 & $3.86 a$ & 9.1 & $11.0 \mathrm{a}$ & 10.78 & $12.40 \mathrm{a}$ & 4.17 & $4.76 a$ \\
\hline Paraffin wax & 31.39 & $18.3 \mathrm{c}$ & 4.1 & $3.90 a$ & 9.1 & $10.4 \mathrm{~b}$ & 10.78 & $11.48 \mathrm{a}$ & 4.17 & $4.89 a$ \\
\hline $0.5 \%$ chitosan & 31.39 & $18.3 \mathrm{c}$ & 4.1 & $3.79 a$ & 9.1 & $10.0 \mathrm{~b}$ & 10.78 & $12.10 \mathrm{a}$ & 4.17 & $4.65 a$ \\
\hline $1.0 \%$ chitosan & 31.39 & $20.3 \mathrm{~b}$ & 4.1 & $3.70 a$ & 9.1 & $10.0 \mathrm{~b}$ & 10.78 & $11.00 \mathrm{a}$ & 4.17 & $4.80 \mathrm{a}$ \\
\hline $1.5 \%$ chitosan & 31.39 & $19.9 \mathrm{~b}$ & 4.1 & $3.75 a$ & 9.1 & $10.2 \mathrm{~b}$ & 10.78 & $12.20 \mathrm{a}$ & 4.17 & 4.44a \\
\hline Coconut oil & 31.39 & $22.4 a$ & 4.1 & $4.10 \mathrm{a}$ & 9.1 & $9.50 \mathrm{c}$ & 10.78 & $11.98 \mathrm{a}$ & 4.17 & $4.40 \mathrm{a}$ \\
\hline
\end{tabular}

Values in the same row followed by the same letter are not significantly different $(\mathrm{p}>0.05)$.

Pure coconut oil and castor oil helped in reducing the rate of ripening which results in dissolution of ascorbic acid to dehydro ascorbic acid during storage (Bisen et al., 2012). Initial pH and TSS value was $4.1 \%$ and $9.1 \%$, respectively. At 16 days of storage, $\mathrm{pH}$ decreased slightly and TSS increased moderately ranged from $9.5 \%$ to $11 \%$. Mandarin treated with coconut oil recorded minimum (10.98\%) increase in TSS (Table 1). This was probably due to less concentration of juice because of low transpiration because coating with coconut oil sealed the opening of pore/stomata and controlled the dehydration process of fruits (Kulkarni et al., 2010). Initial value of ascorbic acid, total sugar and reducing

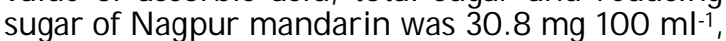
$8.1 \%$ and $3.7 \%$, respectively found by Ladaniya (2011). In this study total sugar and reducing sugar of mandarin was $10.78 \%$ and $4.17 \%$, respectively at initial stage, but these values were increased slightly with storage period.

\section{Decay incidence}

Green mold, Phomopsis stem end rot and Brown rot of mandarin was found as decay causal pathogen of mandarin in this study. The incidence of rot started on 4 days of storage in uncoated/control, $0.5 \%$ and $1.0 \%$ chitosan coated fruit as shown in Fig. 5. On the other hand, rot incidence was initiated in coconut oil coated mandarin at 16 days of storage. Bisen et al., (2012) found no incidence of fungus on kagzi lime coated with coconut oil and liquid paraffin up to 18 days. This was due to the reason that coating (coconut oil and liquid paraffin) sealed the opening on the surface of the fruit there by preventing incidence of moulds.

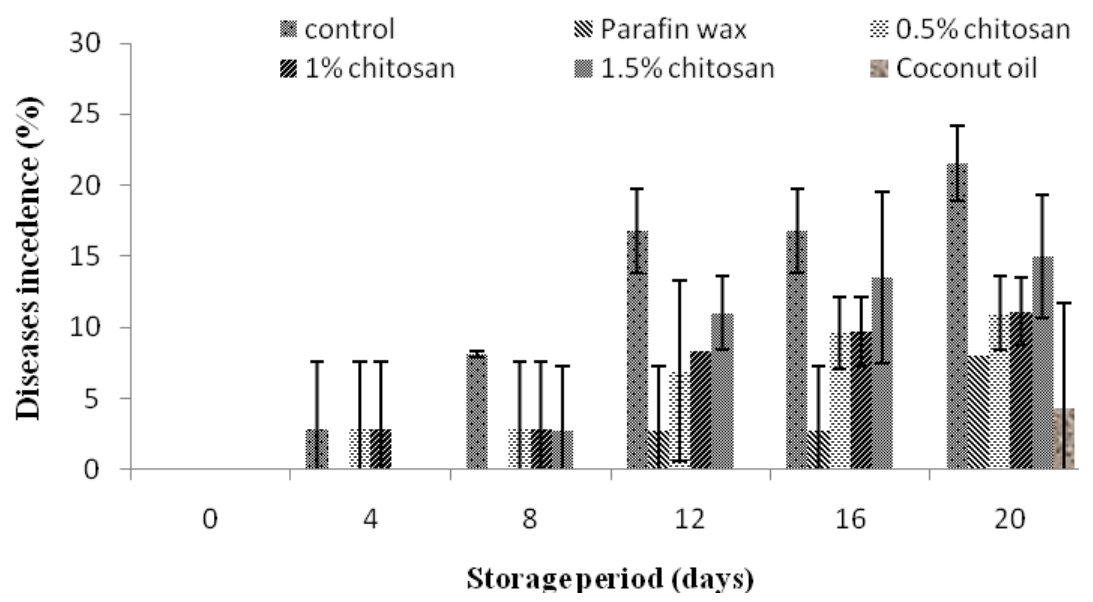

Fig. 5. Effects of edible coatings on disease incidence of mandarin stored at ambient condition $\left(25 \pm 3^{\circ} \mathrm{C}\right.$ and $\left.60-70 \% \mathrm{RH}\right)$. Vertical bars indicate standard deviation. 


\section{Sensory property}

When the storage period was advanced, the sensory attributes such as appearance, flavour, texture and overall acceptability of mandarin was affected adversely under all the treatments. In all attributes, fruits coated with coconut oil secured the highest score (8.1, 7.8, 7.4 and 7.8 in case of appearance, flavour, texture and overall acceptability, respectively) and significantly superior than other treatments as shown in Table 2. Bisen et al. (2012) also found the maximum appearance acceptability of kagzi lime (8.3, 9.0, 8.2 and 7.1) was retained after $0,6,12$ and 18 days of storage period, respectively under pure coconut oil without any objectionable change in appearance followed by liquid paraffin wax stored at room temperature. The acceptability of coconut oil coated fruit was more because the coating maintains the cosmetic appearance of fruits and their acceptability. This may also due to delay in ripening, uniform colour development in fruits under pure coconut oil coating in later period of storage. Similar results were also reported by Mahajan et al. (2005) in kinnow fruits.

Table 2. Effects of edible coatings on sensory quality of mandarin at 16 days of storage period, stored at ambient condition $\left(25 \pm 3^{\circ} \mathrm{C}\right.$ and $\left.60-70 \% \mathrm{RH}\right)$.

\begin{tabular}{ccccc}
\hline Samples & Appearance & Flavour & Texture & Overall acceptability \\
\hline Control & $6.0 \mathrm{c}$ & $6.5 \mathrm{~b}$ & $5.3 \mathrm{c}$ & $5.2 \mathrm{c}$ \\
Paraffin wax & $7.9 \mathrm{a}$ & $7.1 \mathrm{~b}$ & $7.3 \mathrm{a}$ & $7.0 \mathrm{~b}$ \\
$0.5 \%$ chitosan & $7.1 \mathrm{~b}$ & $6.8 \mathrm{~b}$ & $6.1 \mathrm{~b}$ & $6.1 \mathrm{bc}$ \\
$1.0 \%$ chitosan & $7.7 \mathrm{a}$ & $6.8 \mathrm{~b}$ & $7.1 \mathrm{a}$ & $6.5 \mathrm{~b}$ \\
$1.5 \%$ chitosan & $7.8 \mathrm{a}$ & $6.5 \mathrm{~b}$ & $7.0 \mathrm{a}$ & $6.7 \mathrm{~b}$ \\
Coconut oil & $8.1 \mathrm{a}$ & $7.8 \mathrm{a}$ & $7.4 \mathrm{a}$ & $7.8 \mathrm{a}$ \\
\hline
\end{tabular}

Values in the same row followed by the sameletter are not significantly different $(p>0.05)$.

\section{Conclusion}

The physical, chemical and sensory quality of mandarins were significantly and positively influenced by coconut oil coating up to 20 days of storage at ambient condition $\left(25 \pm 3^{\circ} \mathrm{C}\right.$ and 60 $70 \% \mathrm{RH})$. Hence, coating of fruits with pure coconut oil is useful for extending their shelf life by preserving freshness, firmness, weight, colour and overall acceptability. In case of occurrence of microbial decay on surface of fruits, it was observed that pure coconut oil coating delay the appearance of moulds up to 16 days of storage, while untreated fruits were affected by moulds at 4 days of storage.

\section{References}

Aday, M.S. and Caner, C. 2010. Understanding the effects of various edible coatings on the storability of fresh cherry. Packag. Tech. Sci. 23: 441- 456.

AOAC. 1994. Official Methods of Analysis. Association of Official Analytical Chemists. North 19th Street, Suite 20, 16 $6^{\text {th }}$ Edi. Arlington, Virginia, USA. 22209.

Arpaia, M.L. and Kader, A.A. 2000. Mandarin/Tangerine. Recommendations for maintaining postharvest quality. University of California, Davis, CA. http:// postharvest.ucdavis.edu/produce_inf ormation

Bisen, A. and Pandey, S.K. 2008. Effect of post harvest treatments on biochemical and organoleptic constitutes of Kagzi lime fruits during storage. J. Hort. Sci. 3: 53- 56.
Bisen, A., Pandey, S.K. and Joushwa, J. 2008. Effect of gamma irradiation, growth retardant and coatings on storability of lime fruits. Asian J. Hort. 25: 159- 163.

Bisen, A., Pandey, S.K. and Patel, N. 2012. Effect of skin coatings on prolonging shelf life of kagzi lime fruits (Citrus aurantifolia Swingle). J. Food Sci. Tech. 49 (6): 753- 759.

Chahal, S. and Bal, J.S. 2003. Effect of post harvest treatments and packaging on shelflife of Umran ber at cool temperature. J. Res. Punjab Agric. Univ. 40: 363- 369.

Chien, P.J., Sheu, F. and Lin, H.R. 2007. Coating citrus (Murcott tangor) fruit with low molecular weight chitosan increases postharvest quality and shelf life. Food Chem. 100: 1160- 1164.

CIAC. 2002. Strategic Investment Plan (Horticultural Australia). An https documents available at www.ciac.org.

Das, R. and Medhi, G. 1996. Physico-chemical changes of pineapple fruit under certain post harvest treatments. South Indian Hort. 44: 5- 7.

Du, J., Hiroshi, G. and Iwahori, S. 1997. Effects of chitosan coating on the storage of peach, Japanese pear, and kiwifruit. J. Jpn. Soc. Hort. Sci. 66: 15- 22.

Han, C., Zhao, Y., Leonard, S.W. and Traber, M.G. 2004. Edible coatings to improve storability and enhance nutritional value of fresh and frozen strawberries (Fragaria $\mathrm{x}$ ananassa) and raspberries (Rubus ideaus). Postharvest Biol. Tech. 33: 67- 78. 
Jiang, Y.M. and Li, Y.B. 2001. Effects of chitosan coating on postharvest life and quality of longan fruit. Food Chem. 73: 139- 143.

Kulkarni, S.G , Vijayanand, P. and Shubha, L. 2010. Effect of processing of dates into date juice concentrate and appraisal of its quality characteristics. J. Food Sci. Tech. 47: 157161.

Ladaniya, M.S. 2011. Physico-chemical, respiratory and fungicide residue changes in wax coated mandarin fruit stored at chilling temperature with intermittent warming. J. Food Sci. Tech. 48(2): 150- 158.

Mahajan, B.V.C., Bhatt, A.S. and Sandhu, K.S. 2005. Effect of different post harvest treatment on the storage life of kinnow. J. Food Sci. Tech. 42: 296- 299.

Mahfoudhi, N., Chouaibi, M. and Hamdi, S. 2014. Effectiveness of almond gum trees exudate as a novel edible coating for improving postharvest quality of tomato (Solanum lycopersicum L.) fruits. Food Sci. Tech. Int. 20(1): 33-43.

Nasrin, T.A.A. and Anal, A.K. 2015. Enhanced oxidative stability of fish oil by encapsulating in culled banana resistant starch-soy protein isolate based microcapsules in functional bakery products. J. Food Sci. Tech. 52(8): 5120-5128.

Pandey, S.K., Joushwa, J.E. and Bisen, A. 2010. Influence of gamma irradiation, growth retardants and coatings on the shelf life of winter guava fruits (Psidium guajava L.). J . Food Sci. Tech. 47: 124- 127.

Ribeiro, C., Vicente, A.A., Teixeira, J.A. and Miranda, C. 2007. Optimization of edible coating composition to retard strawberry fruit senescence. Postharvest Biol. Tech. 44: 63- 70.

Rosli, H.G., Civello, P.M. and Martinez, G.A. 2004. Changes in cell wall composition of three Fragariaxananassa cultivars with different softening rate during ripening. Plant Physiol. Biochem. 42: 823- 831.

Seehanam, P. and Boonyakiat, D. 2010. Physiological and Physicochemical Responses of 'Sai Nam Phueng' Tangerine to Commercial Coatings. Hort. Sci. 45(4): 605609. 